\title{
Does Algebraic Reasoning Enhance Reasoning in General? A Response to Dudley
}

\author{
Peter Johnson
}

I read with great interest the article "What is mathematics for?" by Underwood Dudley in the May 2010 Notices. Dudley makes a strong case that the importance of algebra in the future careers of most students is exaggerated and should not be used as an argument for the teaching of algebra. I have nothing to add to his argument on this point, but I would in fact take his argument one step further for postsecondary students. At the college level, algebra forms the core content of developmental mathematics courses, and passing a developmental mathematics course or gaining placement at a level beyond developmental mathematics is the usual prerequisite to taking quantitative courses and to graduate. However, for most non-STEM (Science, Technology, Engineering, and Mathematics) majors, the algebra in those developmental courses and placement examinations is not used in a meaningful way later on, even in subsequent mathematics courses they take at the college level. (See [6] for a case study on this point.)

Dudley makes the claims that the main reason to learn algebra is that "mathematics develops the power to reason" ([3], p. 612) and that while "it does not...always succeed," it is still "the best method that we have" ([3], p. 613). I thought that those readers who enjoyed Dudley's article might also want to know what the research on learning

Peter Johnon is associate professor of mathematics at Eastern Connecticut State University. His email address is johnsonp@easternct.edu .

Members of the Editorial Board for Doceamus are: David Bressoud, Roger Howe, Karen King, William McCallum, and Mark Saul.

DOI: http://dx.doi.org/10.1090/noti896 in educational psychology has to say on this point. What Dudley is ultimately claiming for algebra is transfer-that the kind of reasoning that algebra entails will enhance reasoning skills and that those reasoning skills will then transfer to other realms of thinking and understanding. In psychological research, Dudley's transfer would be termed "far transfer": that is, the understanding thus obtained from one domain (algebra) will transfer to another domain quite different in nature.

The study of transfer has a very long history in educational psychology, and the degree to which far transfer occurs has been a contentious issue for many decades, with many claiming that far transfer is rare or nonexistent (for example, see [2]). In order to attempt to bring some consensus to the debate on transfer, Barnett and Ceci [1] proposed a taxonomy for describing transfer. Their taxonomy includes six contexts, and it is interesting to note that the transfer of reasoning from algebra to "general reasoning skills" represents far transfer in five of their six contexts: knowledge domain (from algebra to other disciplines), physical context (mathematics classroom to reasoning in other places), temporal context (generalized reasoning done months or years later), academic context (mathematics to other academic and nonacademic contexts), and modality (the written/symbolic language of algebra to abstract thought).

In their review, Barnett and Ceci include a number of studies of transfer conducted over many decades. They also include a table representing a number of widely cited studies representing their place in the taxonomy using the constructs knowledge domain, physical context, and temporal context. In discussing this table they note that 
"[w]e simply did not find any well-controlled studies testing transfer to a far domain, in a far physical context, and in a far temporal context" ([1], p. 627). Thus there appears to be no research evidence that would support the notion that the reasoning skills obtained from learning algebra will transfer to reasoning in a general context.

Another related way to look at the value of algebraic reasoning would be to consider if algebra has an effect on problem solving or critical thinking. In their comprehensive review of problem solving and transfer, Mayer and Wittrock [8] point out that, in the early twentieth century, the prevailing view in education in the United States was "the doctrine of formal discipline-the idea that certain school subjects such as Latin and geometry improved students' minds by making their thinking more logical and disciplined" (p. 49). Dudley is making the identical claim for algebra.

Based on their review of the research literature, Mayer and Wittrock note that "the lack of documented success at promoting problem-solving transfer suggest that other views [than the doctrine of formal discipline] may be more fruitful" ([8], p. 59). In an updated review of the problemsolving literature ten years later, the same two authors posit three research-based principles of problem solving in their conclusion, two of which are relevant to transfer. Their "domain-specific principle" asserts that "[r]ather than attempting to teach general problem-solving heuristics, it is better to teach problem-solving skills within specific domains" ([9], p. 299). In addition, according to their "near-transfer principle", "[r]ather than expecting problem-solving skills to be applicable to a wide range of problems, it is better to expect that problem-solving skills will be largely restricted with respect to their range of applicability" ([9], p. 299). Their conclusions thus work against the hopes that Dudley has for algebra.

In order to determine what the research literature might say about the effects of algebra on either transfer or problem solving/critical thinking, I did two literature searches using the databases ERIC (for education) and PsycINFO (for psychology), using the descriptors "algebra" and "transfer", and then "algebra" and either "critical thinking", "reasoning”, "logical thinking”, or "problem solving". I did not locate a single study that investigated the transfer of algebraic thinking to other domains. There are some studies that investigate the effects of problem-solving strategies or critical thinking on performance in algebra, but virtually none that "go in the other direction" and investigate the effect of algebraic thinking on problem-solving or critical-thinking. One study that I did locate [5] compared two college algebra classes on their problem solving and critical-thinking skills, but with no comparison data to nonalgebra students, it is not possible to draw any conclusions about the effects of algebraic thinking on those domains. A second study I located from some time ago [4] found that lowachieving algebra students actually outperformed high-achieving students on some kinds of logical syllogisms. This was the complete set of studies on the effects of algebra I was thus able to locate. In addition, I note that the very extensive review of recent research literature on the learning of algebra by Kieran [7] does not contain any studies of the effects of algebra on either far transfer or on problem solving and critical thinking.

There appears to be no research whatsoever that would indicate that the kind of reasoning skills a student is expected to gain from learning algebra would transfer to other domains of thinking or to problem solving or critical thinking in general. The lack of such research evidence does not mean that such transfer does not occur or that algebraic reasoning might not have positive effects on problem solving and critical thinking. However, in light of the conclusions of Meyer and Wittrock [8], [9], until such effects are demonstrated through research, I shall remain a skeptic.

\section{References}

1. S. M. BARNETT and S. J. CECI, When and where do we apply what we learn? A taxonomy for far transfer, Psychological Bulletin 128 (2002), 612-637.

2. D. K. DetTerman, The case for the prosecution: Transfer as an epiphenomenon, Transfer on Trial: Intelligence, Cognition, and Instruction (D. K. Detterman and R. J. Sternberg, eds.), Ablex, Westport, CT, 1993, pp. 1-24.

3. U. DuDLEY, What is mathematics for?, Notices of the Amer. Math. Soc. 57 (2010), 608-613.

4. T. A. EISENBERG, Negation, disjunctive syllogisms, and mathematics achievement, The Journal of Psychology 90 (1975), 69-74.

5. B. Elliott, K. Oty, J. McArthur, and B. Clark, The effect of an interdisciplinary algebra/science course on students' problem solving skills, critical thinking skills and attitudes towards mathematics, International Journal of Mathematics Education in Science and Technology 32 (2001), 811-816.

6. P. JoHnson, What are we developing? A case study of a college mathematics program, School Science and Mathematics 107 (2007), 279-292.

7. C. KIERAN, Learning and teaching algebra at the middle school through college levels: Building meaning for symbols and their manipulation, Second Handbook of Research on Mathematics Teaching and Learning (F. K. Lester Jr., ed.), Information Age, Charlotte, NC, 2007, pp. 707-762.

8. R. E. MAYER and M. C. WitTrock, Problem-solving transfer, Handbook of Educational Psychology (D. C. Berliner and R. C. Calfee, eds.), MacMillan, NY, 1996, pp. 47-62.

9. ___ Problem solving, Handbook of Educational Psychology, 2nd ed. (P. A. Alexander and P. H. Winne, eds.), Erlbaum, Mahwah, NJ, 2006, pp. 287-303. 